\title{
ACCOUNTING PRACTICE TRANSPARENCY AND FIRM VALUE OF EXPORTING GEM AND JEWELRY BUSINESSES IN THAILAND
}

Wareewan Charoenroop, Mahasarakham Business School Mahasarakham University, Thailand Phapruke Ussahawanitchakit, Mahasarakham Business School Mahasarakham University, Thailand

\author{
dx.doi.org/10.18374/CBR-1-1.4
}

\begin{abstract}
This study investigates the effects of accounting practice transparency, information advantage and decision making effectiveness on firm value of exporting gem and jewelry businesses in Thailand. Sustainable vision, governance awareness, stakeholder expectation, and ethical commitment become the antecedents of accounting practice transparency by using ethical commitment as the moderator. A questionnaire is used as the instrument for data collection from accounting executives and accounting managers of each firm which are the key informants and, regression analysis is employed to examine all hypotheses of this study. The data are collected from the sample of 104 exporting gem and jewelry businesses in Thailand. The results indicate that some dimensions of accounting practice transparency influence information advantage, decision making effectiveness, and firm value. And, it is noteworthy that one of the dimensions of accounting practice transparency is financial reporting preparation quality which has significant positive effects on information advantage, decision making effectiveness, and firm value. The results also show that information advantage and decision making effectiveness have an effect on firm value. Furthermore, the antecedents of this study have significant positive effects on accounting practice transparency except ethical commitment. In addition, the moderator in this study does not affect the aforementioned relationships, except ethical commitment is positively moderated by the sustainable vision â $\epsilon^{\prime \prime}$ financial reporting preparation quality relationship. Theoretical and managerial contributions are explicitly provided. The conclusion, limitations and directions for future research are also included.
\end{abstract}

Keywords: Accounting Practice Transparency, Accounting Standard Implementation Accuracy, Regulation Awareness Focus, Information Usefulness Concerns, Financial Reporting Preparation Quality, Firm Value 